Earth Common Journal Special Issue

$e^{3}=$ earth education economics

1st PRME Canada Regional Meeting held on June 12, 2013

MacEwan University, School of Business

Volume 3, Number 2, September 2013

\title{
Competing on climate change: An interprovincial, longitudinal review of emerging environmental risks to Canadian homeowners
}

\author{
Adam J. Henley* \\ MacEwan University, Canada
}

\begin{abstract}
In an era of accelerated climate change, Canadian homeowners face growing financial exposures to environmental risks, and climate-related property damage now represents the largest aggregate cause of losses in the global insurance industry (Mills, 2012, p. 1424). This study presents data regarding hydrological, meteorological, and wildfire disasters occurring in Canadian provinces from 1970-2010. The rising incidence of natural disasters suggests that they are affecting an increasing number of Canadians across all provinces. In light of this data, the researcher recommends that Canadian insurers implement a "4-C" strategy to help reduce the human impact of future natural disasters: (1) Coaching local communities to adapt to climate change; (2) Consensus-building around common consumer risks; (3) Collaborating with governments to protect against catastrophic losses; and (4) Cooperating with consumers to co-insure frequent events. Finally, it is recommended that risk capital be invested carefully and sustainably, so that the 4-Cs is customized to address emerging challenges specific to each climate zone.
\end{abstract}


The resultant impacts of climate change are, to a large extent, unpredictable, uneconomical, and unsustainable to insure. Direct losses from floods, severe thunderstorms, and other catastrophic weather events now average $\$ 50$ billion per year among insurers globally (Mills, 2012, p. 1424). Despite the increasing financial burden of climate change, Canadian consumers continue to demand innovative coverage options from property insurers in order to cover a broader range of environmental risks (InsuranceWest, 2013, p. 24). The impetus behind new consumer expectations suggests homeowners are faced with new and growing exposures to environmental risks.

River overflows, hurricanes, and sustained rainfalls are now occurring in areas with limited resources devoted to disaster response, and insurers are starting to feel the financial strain. In 2011, Canadian insurers paid $\$ 1.7$ billion as a direct result of water damage, with most of the claims occurring after periods of increased precipitation, severe storms, and resultant sewage back-up. The large rise in claims has caused water damage to surpass fire as the primary cause of insured losses (Institute for Catastrophic Loss Reduction, 2012, p. 7). Further compounding the financial impact of these claims is the sustained increase in market value of Canadian residential properties: the average market value of owned Canadian dwellings was $\$ 303,500$ in 2008, a 423\% increase from 1982 (Chawla, 2011, p.11). Emerging environmental risks, when combined with the rising value of residential properties, impose a significant financial burden on Canadian insurance companies.

Historically, the framework for property insurance has reflected the risk of fire loss in urbanized settings. American fire insurers are said to have taken 130 years to achieve relative certainty when insuring the risk of fire (Baranoff, 2005, p. 563). Within Canada, property insurance was formally graded by its fire risk following a major fire in Toronto in 1904 (SCM Group Limited, 2004, p. 1). Insurers constantly adapted to emerging risks to property brought on by urbanization processes and advocated for improved water infrastructure and firefighting capacity in communities (SCM Group Limited, 2004, p. 1).

Canadian property insurers continue to be predisposed to a pricing model that focuses on fire loss. For example, the Public Fire Protection Classification is an industry standard for rating property insurance by a community's level of protection against fire (SCM Group Limited, 2004, p. 2). Provincial insurance regulators also mandate comprehensive coverage for fire losses while allowing private markets the flexibility to determine coverage for other risks. Alberta, for example, prohibits any exclusions within property insurance contracts for reasonable circumstances that may lead to fire losses (Insurance Act R.S.A., 2000, s. 545-3). Most property insurers also choose to provide 
generous coverage for losses coincident with meteorological events, such as wind and hail damage. Canadian insurers, however, currently limit their exposure to water damage losses in basic property insurance contracts.

Preliminary reports suggest that property insurers are coping with a fundamental shift in the underlying reasons why property insurance exists. Beyond fire risks, climate change continues to broaden the number of potential disasters that cause catastrophic loss (Leurig, 2011, p. 9). Additionally, increased precipitation is a common factor in many catastrophic flood losses across Canada, and heavy rainfalls are increasingly commonplace. Once-in-20-year rainfalls that occurred 60 years ago are now equivalent to a once-in-10 year risk today (Institute for Catastrophic Loss Reduction, 2012, p. 53). Southern Canada has experienced a $12 \%$ increase in total precipitation since the early 1900s, with similar trends reflected in Canada's North (Zhang, Vincent, Hogg \& Niitsoo, 2011, pp. 425-426). While flood coverage is in high demand, at-risk consumers are often unprepared to pay insurance premiums that are commensurate with their risk. Insurers who do extend coverage to at-risk consumers often assume significant risk to shareholder profits and their own financial solvency.

Today's weather is the best predictor of tomorrow's property insurance contracts. As companies adapt to a changing business landscape, previously standardized policy wordings will be personalized to reflect where an insured homeowner lives. Some companies will exclude complex environmental risks, citing their inherent unpredictability or inability to predict claims costs; however, other companies will begin to offer new coverage options to meet emerging consumer demands (InsuranceWest, 2013, p. 24).

To respond to these emerging market demands, the researcher developed a "4-C" environmental risk management strategy to help insurers respond to a changing climate and address the needs of Canadian property owners. A more consultative, participatory approach, the "4-C" strategy is a four-part strategy that involves open communication with various stakeholders to ensure mutual cooperation. While insuring climate change is difficult, it is a challenge of important consequence to modern insurers.

\section{Methods}

\section{Assumptions}

This study assumes that (1) government-defined natural disasters are catastrophic events, and (2) Canadian insurers will incur potentially severe financial losses from these events.

ECJ Volume 3, No. 2, 2013: $\mathrm{e}^{3}=$ earth education economics 


\section{Hypotheses}

The hypotheses of this study are as follows: 1) The incidence of natural disasters is increasing across all provinces; 2) The total financial impact from hydrological disasters will substantially increase over time, across all provinces, and at a proportionately higher rate compared to meteorological events.

\section{Design}

This study provides a population-level, longitudinal view of national disaster data across all Canadian provinces, from January 1970 to December 2010. Two primary outcomes are considered in this study: (1) natural disaster incidence; and (2) total disaster cost. ${ }^{1}$ Other variables include specific disaster type, climatic zone of occurrence, month and season of occurrence, number of area residents exposed to disaster, and the resultant number of evacuees, insurance payments, and incidental municipal costs. Descriptive statistics are reported when significant or proportionally dissimilar from other categories presented. This study categorized disasters by their defined climate zone rather than by province in order to reflect a truer approximation of climate-related changes (Atmospheric Environment Service, 2012, para. 5).

Selection criteria. Disaster events were eligible for analysis if (a) a natural event of direct importance to a Canadian province occurred; and (b) this same event was declared to be a "significant disaster event" between 1970-2010 in concordance with 2011 definitions (Emergency Management Policy Directorate, 2011, p. 14).

For the purposes of this study, natural events were defined as any hydrological event, meteorological event, or wildfire. Hydrological events include any flood, storm surge, or river overflow, which are the primary causes of a disaster event. Meteorological events consist of winter or summer storms, including hurricanes, typhoons, tropical storms, thunderstorms, and tornados. All disasters were categorized based on event type descriptions provided within the Canadian Disaster Database (Canadian Department of Public Safety, 2013a).

Human-caused and geological incidents were specifically excluded from analysis. Human-caused incidents consist of arson, biological and civil incidents, environmental pollution or contamination, explosions, industrial activities, terrorism, transportation, or any other non-natural events. The Canadian Department of Public Safety (2013b)

${ }^{1}$ All reported financial data are normalized to Canadian 2010 dollars via Statistics Canada Consumer Price Index (CPI) tables.

ECJ Volume 3, No. 2, 2013: $\mathrm{e}^{3}=$ earth education economics 
defined geological incidents as any declared disaster caused by volcanic eruptions, earthquakes, tsunamis, and landslides (para. 1). This study also excluded avalanches from the analysis, as they are natural disasters typically influenced by unusual or special human activities within remote mountain regions and do not represent common risks to Canadian property.

Statistical Analysis. In order to identify any differences between decades, the author of the study conducted univariate linear regressions and non-parametric tests using the STATA statistical package (StataCorp LP, 2011). Any P values which were less than 0.05 were considered statistically significant.

Although originally part of the analysis plan, time-dependent regression was not performed as part of this study. Disaster costs were non-linearly distributed over time and sporadic in the dataset. Additionally, the cumulative financial impact of catastrophic events was not fully independent over time. Variability in cost reporting over time, as well as changes in government policy, violated a key assumption of autoregressive integrated moving average (ARIMA) models. The researcher segmented data per decade-year and performed group-wise comparisons per 10-year period in an effort to normalize cost data.

Data sources. Source data was obtained from the Canadian Disaster Database (Canadian Department of Public Safety, 2013a) and consolidated to provide a description of the location, scope, and financial impact of natural disasters. Disaster data were also merged with Adjusted and Homogenized Canadian Climate Data (Mekis \& Vincent, 2011) to determine the climatic zone for each disaster and percent seasonal deviation from average total precipitation. Consumer Price Index tables were used to normalize financial values to 2010 dollars (Statistics Canada, 2013). Data from remote communities (less than 1,000 people affected) were also removed from the dataset.

\section{Results}

This study reports on 493 natural disasters occurring across all Canadian provinces from 1970-2010. Compared to the 1970-1979 decade, the incidence of natural disasters consistently and substantially rose $20.99 \%, 65.43 \%$, and $92.59 \%$ during the 1980-1989, 1990-1999, and 2000-2009 decades respectively (see Appendix A, Table 1). Additionally, these findings appear to be driven by increases in the incidence of meteorological and wildfire disasters from 1970-2010 (see Appendix B, Figure 2). Even after financial data were normalized to 2010 dollars, the costs incurred from natural disasters remained sporadic between events; however, this was likely attributable to the

ECJ Volume 3, No. 2, 2013: $\mathrm{e}^{3}=$ earth education economics 
different disaster-incidence patterns across climatic zones (as shown in Appendix B, Figure 1). The average annual number of evacuees doubled between 1970 and 2010, although this finding was only significantly associated with wildfire occurrence $(\mathrm{F}(2$, $465)=5.04, p=0.009)$. The number of evacuees was highest in the 2000-2010 decade (median 614; IQR 892); meanwhile, disaster-related mortality and injury were distributed irregularly over time and across climate zones.

On further analysis, the majority of hydrological $(59.05 \%, \mathrm{n}=124)$ and wildfire disasters $(78.69 \%, \mathrm{n}=48)$ occurred when total precipitation deviated $>5 \%$ from its 40 year seasonal average $\left(\chi^{2}(2)=14.32, p=0.001\right)$. When total precipitation was $>10 \%$ under the seasonal average, the rate of wildfire increased $11.13 \%$. These findings indicate the contingent relationship between seasonal precipitation, total financial cost, and disaster incidence (as shown in Appendix B, Figure 3). Findings suggest a link exists between climatic events and natural disaster incidence. This may explain why different disaster incidence patterns were observed between different Canadian climate zones.

\section{Atlantic Canada}

The Atlantic Canada climate zone includes significant portions of the provinces of Nova Scotia, New Brunswick, Prince Edward Island and Newfoundland (Atmospheric Environment Service, 2012, para. 5). From 1970 to 2010, hurricanes and tropical storms have significantly altered the nature of meteorological disasters within this climate zone (see Appendix B, Figure 1). Over a forty-one-year period, 21 disasters occurred due to hurricanes or tropical storms with just over half of these storms occurring between 2000-2010.

Statistically, Atlantic Canada resembled the most homogenous climatic zone. Meteorological events, including direct damage from hurricanes, represented the most frequent disaster declared in the zone $(51.79 \%, \mathrm{n}=58)$ and also yielded severe financial impacts (median $\$ 12,914,287$ ). In terms of property damage, the frequency of hydrological disasters has consistently increased per decade-year, resulting in a median loss of $\$ 9,174,307$ per occurrence between $2000-2010$.

\section{Great Lakes/St. Lawrence Lowlands}

The Great Lakes and St. Lawrence climate zone is centered around major water bodies within Southern Quebec and Ontario (Atmospheric Environment Service, 2012, para. 5). Since the early 1970s, the Great Lakes and St. Lawrence climate zone was the only one to experience negligible increases in disaster incidence (as shown in Appendix

ECJ Volume 3, No. 2, 2013: $\mathrm{e}^{3}=$ earth education economics 
A, Table 1). It is important to note, however, that the Great Lakes and St. Lawrence zone is well populated. From 2000-2010, over 94.23\% of all disasters affected at least 2,500 residents. Therefore, even negligible increases in disaster incidence could result in precipitously larger loss exposures.

No wildfire disasters have been declared in this climate zone during any of the 40 years observed in this study. However, financial losses imposed from hydrological disasters have grown significantly throughout the 1990s (median $\$ 10,678,157$; IQR $\$ 23,088,489)$. Property damage trends in this zone suggest a declining frequency but a significantly higher severity.

\section{Northeastern and Northwestern Forests}

The Northeastern Forest climate zone consists of the inland forested areas of Northern Quebec, Northern Ontario and Northeastern Manitoba (Atmospheric Environment Service, 2012, para. 5). Likewise, the Northwestern Forest climate zone consists of inland forested areas within Northwestern Manitoba, Northern Saskatchewan and Northern Alberta (Atmospheric Environment Service, 2012, para. 5). These zones are substantially similar and were reported as one group by the researcher. From 19702010, 67.86\% of all wildfire disasters in the study occurred within Canada's interior forests, but a significant proportion of these wildfires affected remote areas with less than 2,500 residents $(46.34 \%, \mathrm{n}=19)$. There was also wide disparity in the financial impact of these wildfires. For example, a 1995 forest fire in Northern Saskatchewan caused an estimated $\$ 123,652,454$ million in direct property damage, representing onetenth of disaster costs in the zone from 1990-2010. Floods are also a significant concern in this climatic zone. River basins appear to be at a lower risk of seasonal flooding when total precipitation deviates $<15 \%$ from the 40 -year seasonal average $(z=-7.77$, $\mathrm{p}=0.032)$.

\section{Pacific Coast and South British Columbia Mountains}

The Pacific Coast climate zone consists of the inland coastal areas of British Columbia (Atmospheric Environment Service, 2012, para. 5). As Canada's most moderate climatic zone, the Pacific Coast had relatively few hydrological $(n=13)$ and meteorological $(n=15)$ disasters from 1970-2010. However, $95.38 \%$ of all disasters occurred within zones populated by at least 2,500 residents. Meanwhile, the South British Columbia Mountain climatic zone includes the Southern interior of British Columbia (Atmospheric Environment Service, 2012, para. 5). Hydrological $(n=18)$ and wildfire $(n=9)$ disasters were slightly more common in the South British Columbia 
Mountains' climatic zone. A substantial catastrophic loss also affected this zone in the summer of 2012 when a wildfire near Fraser River and Chilcotin resulted in over $\$ 113$ million in damages. However, both zones experienced significantly lower disaster incidence compared to the other climatic zones $\left(\chi^{2}(12)=124.23, \mathrm{p}<0.001\right)$.

\section{Prairies}

Canada's Prairie climatic zone consists of the southern portions of Manitoba, Saskatchewan and Alberta (Atmospheric Environment Service, 2012, para. 5). Ninetyeight disasters occurred across the Prairie zone from 1970-2010, and over 57.14\% $(n=56)$ were the result of meteorological storms. More significantly, the majority of meteorological disasters in this region affected populations of 2,500 people or more $(87.93 \%, \mathrm{n}=51)$. Exposure to property losses appears to be largely coincident with summer storm events across the Prairies, particularly during periods of increased rainfall.

Only one wildfire, of negligible financial consequence, occurred in the Prairies throughout the 40-year period reviewed in this study. Also, while the incidence of hydrological events had not risen consistently between 1970-2010, losses from floods were highest from 2000-2009 (median \$12,711,389; IQR \$17,974,999). Hydrological disasters have occurred predominantly in Southern Manitoba $(n=21)$ and Alberta $(n=32)$ near major river valleys.

\section{Discussion}

Across all Canadian climate zones, there have been sustained changes in both the incidence and financial severity of natural disasters since the 1970s (see Appendix B, Figure 3). These findings remain considerably important to property insurers who face pressure from the public to expand coverage for emerging-and often unpredictableweather events. Although the incidence of catastrophic events continues to change across Canada, this study presents convincing evidence that increased environmental disasters will continue to impose significant financial burden for property insurers and homeowners.

Coincidentally, Canadian property insurers can begin their adaptation process by extending their own competitive strategies for climate change risks. Even after financial data were normalized to 2010 dollars, the average cost of natural disasters remained sporadic between disaster occurrences. Such variability suggests that the extensive reliance on re-insurance to protect against catastrophic losses is reasonable but increasingly costly (ICLR, 2012).

ECJ Volume 3, No. 2, 2013: $\mathrm{e}^{3}=$ earth education economics 


\section{A “4-C" Strategy for Climate Responsive Insurance}

Canada's climate is changing, and so are the common risks facing today's homeowner. Such drastic changes have created new consumer expectations for property insurance contracts. Water damage has overcome fire as the largest loss cost for property insurance in Canada (Institute for Catastrophic Loss Reduction, 2012, p. 7). Some insurers have opted to adapt coverage options to respond to emerging demands (InsuranceWest, 2013, p. 24); meanwhile, other companies have been reluctant to broaden coverage for climate risks.

This study demonstrates how catastrophic events are becoming more frequent and severe across Canada in light of climate change. The incidence of disasters is increasing across Canada (as shown in Appendix A, Table 1); however, different types of climatic events have resulted in different disaster incidence patterns between provinces. Canadian homeowners are used to standardized property insurance contracts, which are substantially comparable between different provinces and insurance companies. However, the researcher's findings suggest that Canadian disaster risks are becoming far more heterogeneous over time. Property insurance contracts will likely become far more individualized to local loss exposures as insurers adapt to growing climate-related costs.

The following "4-C" strategies can help Canadian insurers adapt to consumer needs while also managing environmental risks:

Coaching local communities to adapt to climate change. Insurers should not discount the substantial impact local communities can have on future loss statistics. A historical review of post-disaster migration in the United States suggests that fewer people live in tornado-prone areas following catastrophic events (Boustan, Kahn, \& Rhode, 2012, p. 242). However, this effect reverses in relation to flooding. Areas prone to overland flooding in the United States continue to experience residual population growth and net in-migration throughout each decade following the disaster (Boustan et al., 2012, pp. 241-242). Insurers can work with municipal governments and civil society to take an active role in preventing unnecessary losses. By becoming involved in urban planning decisions, insurers can remind local leaders of their need to mitigate highly probable environmental risks. For example, local zoning boards in riverside communities should be supported in their efforts to avoid the inappropriate development of flood plains. Through restricted grants, insurers could prioritise their charitable contributions to support the creation of urban parklands in areas that require development restrictions.

ECJ Volume 3, No. 2, 2013: $\mathrm{e}^{3}=$ earth education economics 
Municipal planning boards are integral to moderating future losses incurred by communities. As such, these boards could be provided with industry statistics on loss mitigation techniques. Insurers could also lobby for stricter provincial building codes for municipalities, which, in turn, reduce or prevent loss. This option would work particularly well in Ontario, Quebec, and British Columbia. Within these provinces, the substantial majority of declared disasters occurred in municipalities with 2,500 people or more.

Consensus building around common consumer risks. Substantial evidence suggests that ambiguity - marked primarily by disagreement and uncertainty about a given risk - results in decreased attention placed on potentially useful climate information in everyday decision-making (Cameron, 2005, p. 88; Kousky, 2010, p. 398). Therefore, if the insurance industry wants to incite consumer action on climate change, it must adopt an industry-wide communication plan that builds a consensus understanding of emerging environmental risks. Insurance regulators will require extensive information about the changing nature and distribution of risks to Canadian property resulting from accelerated climate change. Furthermore, the insurance industry itself will have to defend its pricing approach as claims costs begin to rise and rating systems evolve (Tennyson, 2010, p. 42). Informing consumers about their risks by creating consensus opinion within the industry will help others form accurate understandings of environmental risks.

This is a viable option across the Canadian Prairies, where substantial growth in summer storms caused the vast majority of catastrophic events. Insurers can educate consumer markets about the growing climate risk and provide information about which measures protect against storm damage.

Collaborating with government to protect against catastrophic losses. Although new market mechanisms are currently under development to cope with weather losses, insurance companies commonly spread their risk of weather-related losses with re-insurance (Golden, Wang, \& Yang, 2007, p. 323). Access to affordable reinsurance products depends on a region's past loss history, which may be significantly worse in an era of climate change. Kousky, Luttmer, and Zeckhauser (2006) assert that private capital generally supports the functioning of insurance markets in relatively safe markets (p. 75). Markets with frequent climate losses-especially losses that are highly predicable or catastrophic-will likely encounter greater difficulty accessing re-insurance markets in coming years. Insurers should, therefore, advocate for the expansion of government insurance programs in areas that may soon have limited access to private re-

ECJ Volume 3, No. 2, 2013: $\mathrm{e}^{3}=$ earth education economics 
insurance solutions. There is a reciprocal relationship between increased investment in physical assets and government protection within those markets (Kousky, Luttmer \& Zeckhauser, 2006, p.75).

This option would work particularly well in the interior forests of British Columbia, Alberta, Saskatchewan, Ontario, and Quebec, where the financial loss (but not the incidence) of wildfire continues to grow exponentially. For example, insurers could lobby the federal government to institute a government insurance program to re-insure the growing costs of catastrophic wildfires within these provinces. Planning to insure catastrophic wildfires requires extensive re-insurance, which may be prohibitively expensive within the private market. In exchange for this government protection, insurers would be able to offer broader and more predictable protection to consumers. Storm surge protection is one additional coverage option that consumers in Canada's interior forests would benefit from.

Cooperating with consumers to co-insure frequent events. Given substantial climatic shifts, it is inevitable that some financial losses will be absorbed by the consumer. There is the argument, however, that self-insurance for catastrophic events exposes even wealthy individuals to disadvantageous economic loss (Lee, 2010, p. 170). The inferior nature of self-insurance as a risk-management strategy for major losses is apparent.

That being said, homeowners in Atlantic Canada will require some level of selfinsurance to cope with the growing incidence and severity of coastal storms. As the level of self-insurance rises, however, the remaining pool of applicants generally report uninsurable background risks (Crocker \& Snow, 2008, p. 159). For example, hurricane damage is currently covered within most homeowner's contracts but not resulting water damage from the storm. Adverse selection pressures are expected to grow within the Atlantic Canadian market place as less vulnerable homeowners seek greater amounts of self-insurance for hurricane risks. .

The Atlantic Canadian climate zone will most likely encounter adverse selection pressures following hydrological disasters. That is, homeowners living near low-lying coastal areas will inevitably desire comprehensive coverage for storm surges and floods. Those in high elevation areas, however, will likely reject the high cost of insurance for such coverage. In this instance, the cross-subsidization of risks can be avoided through the careful application of hurricane deductibles (Crocker \& Snow, 2008, p. 138; Petrolia, Landry, \& Coble, 2013, p. 242). 


\section{Conclusion}

Significant variation in natural disaster incidence and severity exists across Canada with one consistent finding: natural disasters have become more common and more severe across all climatic zones since the early 1970s. Each climatic zone, however, yields vastly different disaster incidence patterns over time. While discussing the fiscal impact of emerging environmental risks, one industry report states: "This changing climate will profoundly alter insurers' business landscape, affecting the industry's ability to price physical perils, creating potentially vast new liabilities and threatening the performance of insurers' vast investment portfolios" (Leurig, 2011, p. 9). This study has adopted a similar viewpoint. Canada's insurance industry, as it exists today, will soon undoubtedly face profound pressures to custom-tailor currently standardized policies, based in large part on where an insured homeowner lives.

Change is perhaps the only constant for Canada's property insurance market. In this study, the researcher has briefly examined four strategies to cope with climate-related changes in catastrophic events. This strategy was designed by the researcher to reflect a more consultative, participative approach to environment risk management. By focussing on local consumers and communities, the four-part strategy can help insurers to develop stronger community partnerships while addressing the problem of climate change. A "4-C" environmental risk management strategy is a sustainable solution that can help Canadian insurers weather the coming storm.

\footnotetext{
*Author: Adam Henley is currently completing his Management Studies diploma at MacEwan University, majoring in Insurance and Risk. Management. He aspires to become a market research analyst. Prior to entering the field of insurance, Adam graduated from Trent University in 2009 with a Bachelor of Science in Nursing degree.

Acknowledgements:

I would like to express thanks to Professor Teresa Costouros, Curriculum Coordinator for Insurance Programs at MacEwan University for her encouragement while exploring emerging insurance issues.
}

ECJ Volume 3, No. 2, 2013: $\mathrm{e}^{3}=$ earth education economics 


\section{References}

Atmospheric Environment Service (2012, July 12). [Graph illustration of climatic zones in Canada]. 2012 Climate trends and variations bulletin for Canada: Summary. Ottawa: Environment Canada. Retrieved from http://www.ec.gc.ca/adsccmda/default.asp?lang $=$ En\&n=77842065-1

Baranoff, D. (2005). Shaped by risk: The American fire insurance industry, 1790-1920. Enterprise \& Society, 6(4), 561-570. doi:10.1093/es/khi091

Boustan, L. P., Kahn, M. E., \& Rhode, P. W. (2012). Moving to higher ground: Migration response to natural disasters in the early twentieth century. American Economic Review, 102(3), 238-244. doi:10.1257/aer.102.3.238

Cameron, T. A. (2005). Updating subjective risks in the presence of conflicting information: An application to climate change. Journal of Risk \& Uncertainty, 30(1), 63-97. doi:10.1007/s11166-005-5833-8

Canadian Department of Public Safety (2013a). Canadian Disaster Database, English Version [CSV File with Data Definitions, 1970-2011]. Retrieved from http://cdd.publicsafety.gc.ca/

Canadian Department of Public Safety (2013b, July). Reference table for symbols and definitions. Canadian Disaster Database, English Version. Retrieved from http://www.publicsafety.gc.ca/prg/em/cdd/cdd-symb-eng.aspx

Chawla, R. K. (2011). The distribution of mortgage debt in Canada. Ottawa: Statistics Canada. Retrieved from http://www.statcan.gc.ca/

Crocker, K. J., \& Snow, A. (2008). Background risk and the performance of insurance markets under adverse selection. Geneva Risk and Insurance Review, 33(2), 137-160. Retrieved from http://www.palgrave-journals.com/grir/index.html

Emergency Management Policy Directorate (2011). In Ministers Responsible for Emergency Management (Ed.), An emergency management framework for Canada: Second edition (2nd ed.). Ottawa: Public Safety Canada.

Golden, L. L., Wang, M., \& Yang, C. (2007). Handling weather related risks through the financial markets: Considerations of credit risk, basis risk, and hedging. Journal of Risk \& Insurance, 74(2), 319-346. doi:10.1111/j.1539-6975.2007.00215.x

Institute for Catastrophic Loss Reduction. (2012, June). Telling the weather story: A joint report. Insurance Bureau of Canada. Retrieved from http://www.ibc.ca/en/natural_disasters/documents/mcbean_report.pdf. 
Insurance Act, Revised Statutes of Alberta. (2000, c I-3). Retrieved from http://canlii.ca/t/51v9w

InsuranceWest (2013, January). Seeking ways to mitigate the challenges of climate change. (2013, January 2013). InsuranceWest, 18, 28-29.

Kousky, C. (2010). Learning from extreme events: Risk perceptions after the flood. Land Economics, 86(3), 395-422.

Kousky, C., Luttmer, E. F., \& Zeckhauser, R. J. (2006). Private investment and government protection. Journal of Risk \& Uncertainty, 33(1), 73-100. doi:10.1007/s11166-006-0172-y

Lee, K. (2010). Wealth effects on self-insurance. Geneva Risk and Insurance Review, 35(2), $160-171$.

Leurig, S. (2011, September). Climate risk disclosure by insurers-Evaluating insurer responses to the NAIC Climate Disclosure Survey. A CERES report. Retrieved from http://www.ceres.org/resources/reports/naic-climate-disclosure

Mekis, É, \& Vincent, L. A. (2011). An overview of the second generation adjusted daily precipitation dataset for trend analysis in Canada. Atmosphere-Ocean, 49(2), 163-177. doi: 10.1080/07055900.2011.583910

Mills, E. (2012). The greening of insurance. Science, 338(12), 1424-1425. doi: $10.1126 /$ science. 1229351

Petrolia, D. R., Landry, C. E., \& Coble, K. H. (2013). Risk preferences, risk perceptions, and flood insurance. Land Economics, 89(2), 227-245.

SCM Group Limited (2004, September). Fire Underwriters Survey (FUS) and the importance of insurance gradings. Risk Tech, 1(3), 1-4. Retrieved from: http://www.fireunderwriters.ca/articles/RiskTechVolume1Issue3_FUS.pdf

StataCorp LP. (2011). STATA 12 (1 st ed.). Texas, USA.

Statistics Canada. (2013). Table 326-0021: Consumer Price Index (CPI), 2010 basket, annual. [Pivot Table, National Data, 1970-2010]. CANSIM (database). Retrieved from http://www5.statcan.gc.ca/cansim/

Tennyson, S. (2010). Incentive effects of community rating in insurance markets: Evidence from Massachusetts Automobile insurance. Geneva Risk and Insurance Review, 35(1), 19-46.

Zhang, X., Vincent, L.A., Hogg, W.D. and Niitsoo, A. (2000). Temperature and precipitation trends in Canada during the 20th Century. Atmosphere-Ocean, 38(3), 395-429. doi:10.1080/07055900.2000.9649654 
Appendix A: The Disaster Incidence Among Canada's Climatic Zones

Table 1: Disaster Incidence of Canada's Climate Zones from 1970-2010

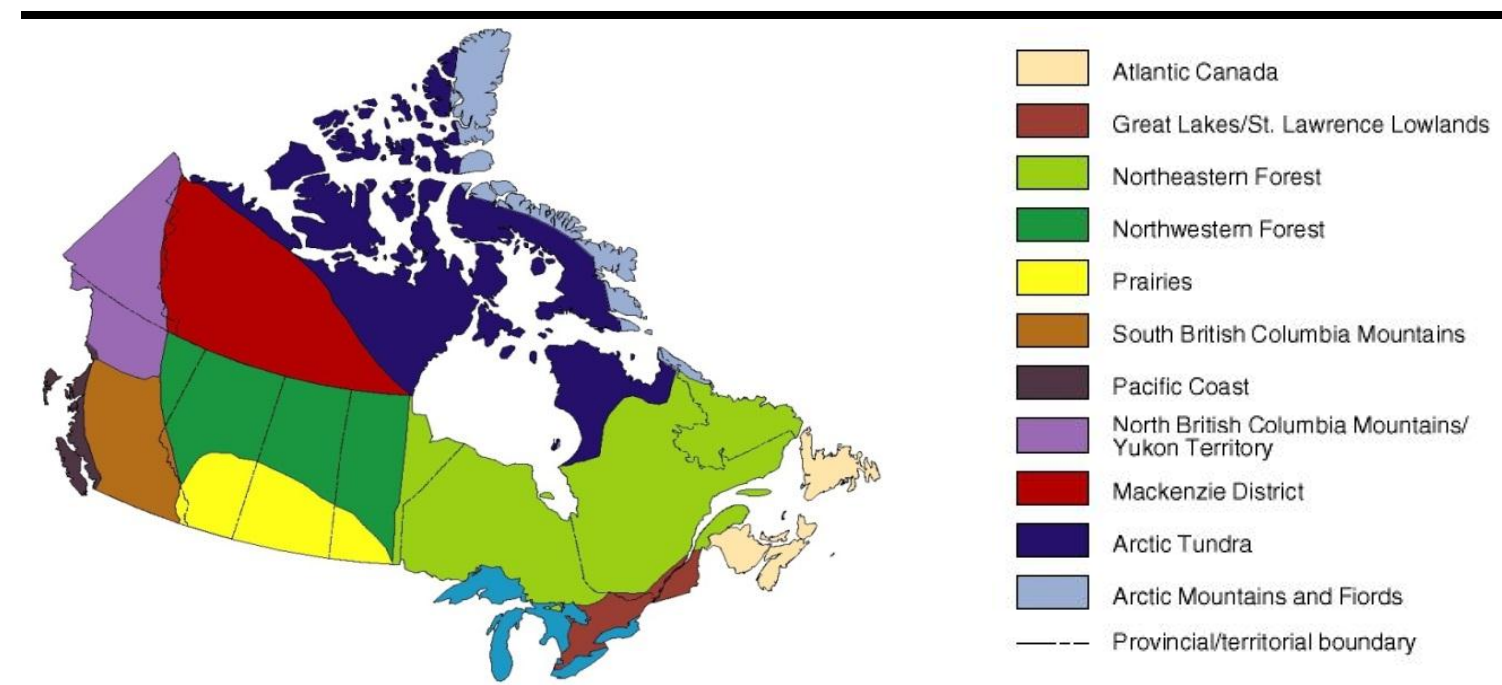

(Atmospheric Environment Service, 1998)

Count ( $\%$ of Cumulative Incidence)

\begin{tabular}{|c|c|c|c|c|c|c|}
\hline & & \multicolumn{4}{|c|}{ Disaster Incidence } & \multirow[b]{2}{*}{ Total } \\
\hline & & $\begin{array}{c}1970- \\
1979\end{array}$ & $\begin{array}{c}1980- \\
1989\end{array}$ & $\begin{array}{c}1990- \\
1999\end{array}$ & $\begin{array}{c}2000- \\
2009\end{array}$ & \\
\hline \multirow{2}{*}{ Atlantic Canada } & $\mathbf{n}$ & 24 & 19 & 20 & 42 & 105 \\
\hline & $\%$ & 22.86 & 18.10 & 19.05 & 40.00 & 100.00 \\
\hline \multirow{2}{*}{ Great Lakes and St. Lawrence } & $\mathbf{n}$ & 24 & 26 & 28 & 23 & 101 \\
\hline & $\%$ & 23.76 & 25.74 & 27.72 & 22.77 & 100.00 \\
\hline \multirow{2}{*}{ Northeastern Forest } & $\mathbf{n}$ & 5 & 12 & 15 & 22 & 54 \\
\hline & $\%$ & 9.26 & 22.22 & 27.78 & 40.74 & 100.00 \\
\hline \multirow{2}{*}{ Northwestern Forest } & $\mathrm{n}$ & 5 & 10 & 10 & 23 & 48 \\
\hline & $\%$ & 10.42 & 20.83 & 20.83 & 47.92 & 100.00 \\
\hline \multirow{2}{*}{ Pacific Coast } & $\mathbf{n}$ & 4 & 6 & 10 & 10 & 30 \\
\hline & $\%$ & 13.33 & 20.00 & 33.33 & 33.33 & 100.00 \\
\hline \multirow{2}{*}{ Prairies } & $\mathrm{n}$ & 16 & 21 & 37 & 24 & 98 \\
\hline & $\%$ & 16.33 & 21.43 & 37.76 & 24.49 & 100.00 \\
\hline \multirow{2}{*}{ South B.C. Mountains } & $\mathrm{n}$ & 3 & 4 & 14 & 12 & 33 \\
\hline & $\%$ & 9.09 & 12.12 & 42.42 & 36.36 & 100.00 \\
\hline \multirow{2}{*}{ Canadian Total } & $\mathrm{n}$ & 81 & 98 & 134 & 156 & 469 \\
\hline & $\%$ & 17.27 & 20.90 & 28.57 & 33.26 & 100.00 \\
\hline
\end{tabular}

ECJ Volume 3, No. 2, 2013: $\mathrm{e}^{3}=$ earth education economics 
Appendix B: Disaster Patterns and Frequency Among Canada's

Climatic Zones

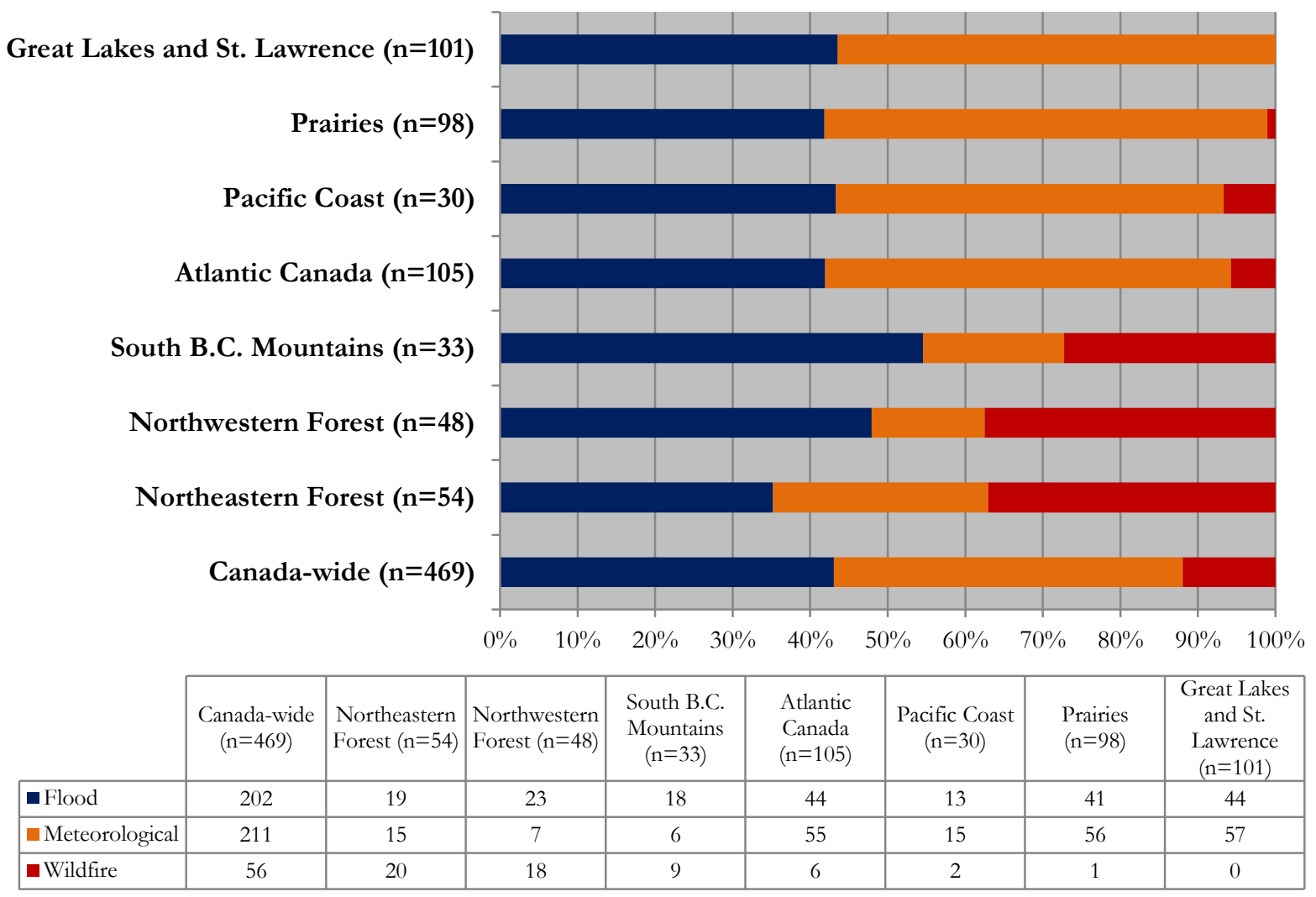

Figure 1. Disaster patterns for Canada's climate zones.

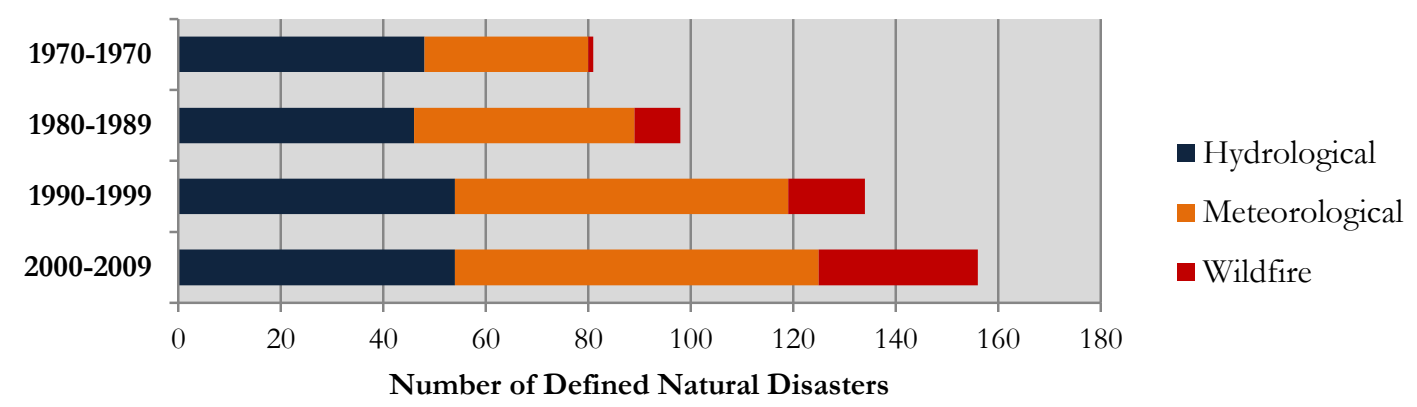

Figure 2. Disaster frequency from 1970-2010.

ECJ Volume 3, No. 2, 2013: $\mathrm{e}^{3}=$ earth education economics 

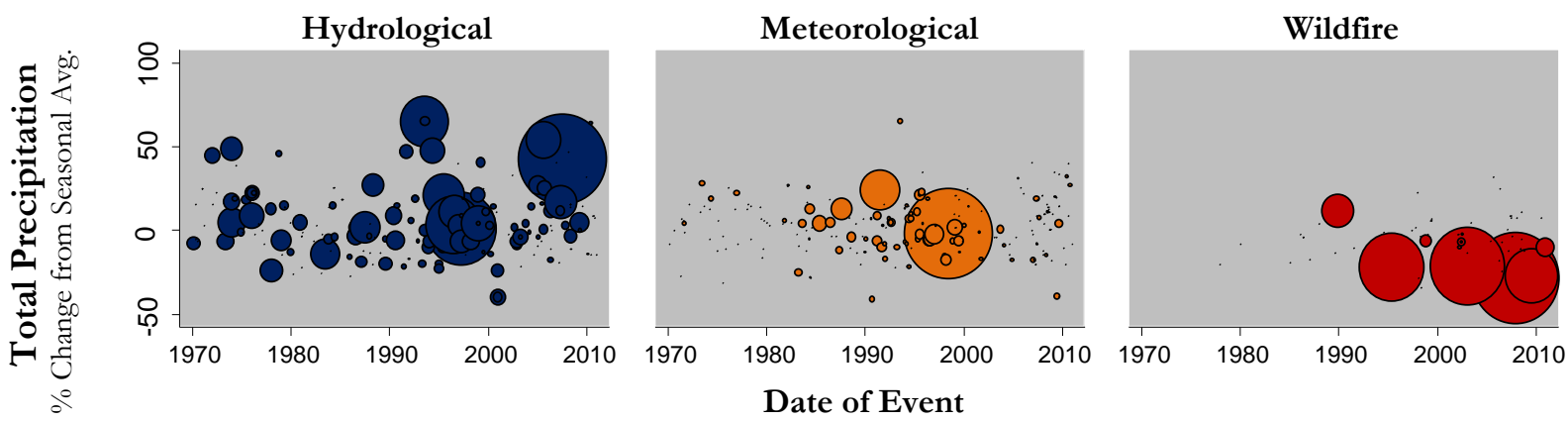

(Observations weighted by Normalized Total Cost, 2010 Dollars)

Figure 3. Disaster frequency and severity by seasonal precipitation levels. 